\title{
Distal intestinal obstruction syndrome in cystic fibrosis treated by oral intestinal lavage, and a case of recurrent obstruction despite normal pancreatic function
}

\author{
A C DAVIDSON, K HARRISON, C L STEINFORT, D M GEDDES \\ From the London Chest and Brompton Hospitals, London
}

ABSTRACT An oral intestinal lavage solution has been successfully used in the treatment of six patients with chronic distal intestinal obstruction syndrome (previously referred to as meconium ileus equivalent) complicating cystic fibrosis and a further case of recurrent small bowel obstruction $\bar{E}_{\bar{E}}$ The patient with recurrent obstruction is unusual in having no evidence of pancreatic maldigestion, which previously has been considered a prerequisite for the syndrome.

A symptom complex of recurrent abdominal pain, anorexia, and occasionally weight loss is the commonest manifestation of distal intestinal obstruction syndrome (often refered to as DIOS, and previously known as meconium ileus equivalent) occurring in an adult with cystic fibrosis. An indentable caecal mass may be palpable in the right iliac fossa with or without symptoms. Alternatively distal intestinal obstruction syndrome may present acutely with abdominal distension, pain, and vomiting secondary to distal small bowel or proximal large bowel obstruction. The syndrome is common, occurring in $10-20 \%$ of patients. Although multiple factors appear to play a part in its development, ${ }^{2}$ malabsorption secondary to the specific pancreatic disease of cystic fibrosis is considered paramount. It has not previously been described in the $10-15 \%$ of patients without obvious pancreatic disease, ${ }^{1-3}$ and control of steatorrhoea reduces its frequency. ${ }^{4}$

There is no clearly superior form of treatment for established distal intestinal obstruction syndrome, although surgery is best avoided. ${ }^{5}$ Conventional treatment is to give either $N$-acetylcysteine or gastrografin both by enema and by mouth. ${ }^{15-8}$ Although probably effective, in our experience enemas are poorly tolerated by patients and oral treatment does not cause rapid relief of symptoms. Cleghorn et al $^{9}$ recently reported the use in this syndrome

Address for reprint requests: Dr A C Davidson, Department of Medicine, St Thomas's Hospital, London SE1 7EH.

Accepted 28 November 1986 of an isotonically balanced solution containing a nonabsorbable high molecular weight glycol. This intestinal lavage solution has previously been used for bowel preparation before colonoscopy. ${ }^{10}$ Although Cleghorn et al did not recommend the use of this method in established bowel obstruction, we haveo used it successfully in one patient after the failure of conventional treatment and also in a further six patients with chronic distal intestinal obstruction syn drome. We also report the recurrent development of acute obstruction in the absence of steatorrhoea in aो patient not having pancreatic supplements. This sug $x$ gests that other factors, such as abnormal water and electrolyte secretion or altered bowel motility and function, may be important in the pathogenesis of the? syndrome.

\section{Methods}

\section{LAVAGE}

The lavage solution* was prepared in the hospitah pharmacy, the composition being similar to thaf described by Davis et $\mathbf{l}^{10}$ and consisting of sodium ${ }^{\omega}$ $125 \mathrm{mmol} / \mathrm{l}$, sulphate $40 \mathrm{mmol} / 1$, chloride $35 \mathrm{mmol} / 1$, bicarbonate $20 \mathrm{mmol} / 1$, potassium $10 \mathrm{mmol} / 1$, an\& polyethylene glycol $80 \mathrm{mmol} / \mathrm{l}$. The sulphate conten was inaccurately reported by Cleghorn et al. ${ }^{9}$ The molecular weight of the polyethylene glycol we

*Although the lavage solution is commercially produced (Golytelip⿱ produced by Travenol and Colyte produced by Reed and Carnick)? neither is at present available in Britain; polyethylene glycol may b. obtained from Sigma Chemical Co Ltd, Fancy Rd, Poole, Dorset. 
Details of patients with distal intestinal obstruction syndrome and of response to treatment by intestinal lavage

\begin{tabular}{|c|c|c|c|c|c|c|}
\hline Patient No & $\operatorname{Age}(y)$ & $\begin{array}{l}\text { Faecal } \\
\text { fat }(g / \text { day })\end{array}$ & Treatment & Symptoms & $\begin{array}{l}\text { Lavage } \\
\text { fluid (litres) }\end{array}$ & $\begin{array}{l}\text { Time in } \\
\text { hospital (days) }\end{array}$ \\
\hline 1 & 18 & $2 \cdot 5$ & Pancrex & $\begin{array}{l}6 \text { mo recurrent pain; subacute } \\
\text { obstruction (1) }\end{array}$ & 10 & $5^{*}$ \\
\hline 2 & 20 & $4 \cdot 3$ & Cimetidine, pancrease & $\begin{array}{l}2 \text { y recurrent pain; intermittent caecal } \\
\text { mass; constipation }\end{array}$ & 3 & $6^{*}$ \\
\hline 3 & 20 & $3 \cdot 6$ & Pancrease, cimetidine & $\begin{array}{l}10 \text { y recurrent pain; intermittent caecal } \\
\text { mass }\end{array}$ & 2 & \\
\hline 4 & 33 & $\begin{array}{l}38 \cdot 5 \\
\text { (Mar 85) } \\
15 \cdot 2 \\
(\text { Jun 85) }\end{array}$ & $\begin{array}{l}\text { Pancrease, cimetidine } \\
\text { (since Mar 85) }\end{array}$ & 4 y recurrent pain; intermittent mass & $4 \dagger$ & 2 \\
\hline 5 & 19 & $4 \cdot 3$ & $\begin{array}{l}\text { Pancrex, cimetidine } \\
\text { acetylcysteine }\end{array}$ & $\begin{array}{l}2 \text { y recurrent pain; subacute obstruction (2); } \\
\text { intermittent mass }\end{array}$ & 5 & 3 \\
\hline 6 & 18 & & Pancrease, cimetidine & $\begin{array}{l}4 \text { mo right sided abdominal pain } \\
\text { pain worse on eating }\end{array}$ & $\begin{array}{l}8 \\
6\end{array}$ & $\begin{array}{l}5 \\
9 *\end{array}$ \\
\hline 7 & 22 & $1 \cdot 8$ & Nil (Pancrease) & Acute obstruction (2) & $\begin{array}{l}5 \dagger \\
4\end{array}$ & $\begin{array}{r}42 \\
2\end{array}$ \\
\hline
\end{tabular}

*Hospitalisation also necessary for coexistent chest infection.

†By nasogastric tube.

obtained was 3350 , while that used by Davis et al ${ }^{10}$ was 4000 and by Cleghorn etal 3500 . These differences are unlikely to be important, although it is essential that the polyethylene glycol is chemically pure and does not contain any low molecular weight glycols, which otherwise could be absorbed through the intestinal mucosa.

Generally 4-6 litres were administered by mouth at a rate of 1 litre an hour. Concentrated fruit juice was used to improve the taste. Alternatively, the solution was given via a nasogastric tube. Prophylactic antiemetics (metoclopramide, $10 \mathrm{mg}$ intramuscularly) were given routinely. Treatment was considered complete when fluid only was passed from the rectum and symptoms had resolved.

\section{PATIENTS}

Six patients presented with the more usual form of distal intestinal obstruction syndrome, complaining of recurrent abdominal pain in association with anorexia, weight loss, and constipation. Vomiting and abdominal distension were occasional features, as was the presence of a caecal mass. Symptoms had been recurrent in four cases and obstruction had occurred in two of these patients previously. In the other two cases symptoms were of recent onset but no other cause for abdominal pain was discovered. The patients' details and the amounts of lavage solution used are given in the table. Although a diagnosis of distal intestinal obstruction syndrome was thought established in all of the cases, one patient in retrospect may have simply had gross constipation. No precipitating cause was apparent in three of the patients, but infection may have been the precipitating cause in the other three.

\section{Results}

Pain and anorexia were rapidly relieved in all cases, but complete radiological bowel clearance was not always achieved. Nausea (without vomiting) and a temporary increase in abdominal discomfort were the only side effects, although metoclopramide induced oculogyric crisis occurred in one patient and should perhaps be regarded as a complication. No electrolyte disturbances occurred after lavage and patients' weight changes were minor, suggesting little or no exchange of fluid across the intestinal mucosa. Symptoms have not recurred during six to 15 weeks' follow up. Steatorrhoea was not apparent in any of the patients at the time they developed symptoms, and in the absence of any other effective prophylactic measure no changes in treatment were made.

\section{CASE REPORT}

The patient presenting with acute obstruction is given in detail because there are several unusual features. Patient 7 was a 22 year old man who suddenly developed acute abdominal pain, distension, and vomiting. He was taking no pancreatic supplements (he had a normal faecal fat excretion rate two months before admission) and is of normal weight ( $77 \mathrm{~kg})$ and height $(1.83 \mathrm{~m})$. Cystic fibrosis was diagnosed on the basis of recurrent chest infections, a sweat sodium concentration of $118 \mathrm{mmol} / \mathrm{l}$, and a positive family history (his sister died at the age of 12 from cystic fibrosis). After admission to another hospital he underwent laparotomy, which showed mucofaecal impaction of the terminal ileum. He was transferred postoperatively for further management. Despite conventional treatment (intravenous fluids, gastric aspi- 
ration, and $N$-acetylcysteine orally and rectally), abdominal symptoms persisted. Four weeks after the original presentation, he again developed complete obstruction with gastric aspiration of up to three litres a day. An erect abdominal radiograph showed distended loops of bowel with multiple fluid levels. Although pancreatitis was provisionally diagnosed (serum amylase 1640 units/l (normal $<400$ units/l)), his condition was unchanged one week later even though the serum amylase concentration had returned to normal. At this stage intestinal lavage was attempted, initially only one litre of the lavage solution being given via-the nasogastric tube over five hours. This was well tolerated and resulted in the passage of a quantity of faecal material. The following day a further three litres of lavage solution was given over six hours with the passage of further faecal material, rapid resolution of abdominal symptoms, and considerable radiological improvement. On discharge from hospital he was treated with pancreatic supplementation (despite the absence of steatorrhoea). Three months later he again developed acute obstruction and was successfully treated by the lavage solution, being discharged from hospital two days later. He has subsequently used the lavage solution at home on one further occasion.

\section{Discussion}

Except for patient 7 these patients are typical, being teenagers with recurrent infection and chronic respiratory disability; steatorrhoea had been found at some stage. Pancreatic supplements had been prescribed in sufficient amounts to control the steatorrhoea (see table) and this was achieved without fat avoidance in four of the six cases according to a simple inquiry. Intestinal lavage was highly effective symptomatically but radiological clearance of the bowel was not always complete. The only appreciable complication was the case of oculogyric crisis secondary to the use of metoclopramide. Perhaps the routine use of domperidone might be wise in view of the age of the patients. Although concern has been expressed about the danger of possible absorption of polyethylene glycol, ${ }^{12}$ these fears appear to be unfounded..$^{13}$ The lavage technique offers several advantages over more conventional treatment. The time spent in hospital was short since the treatment was rapidly effective, and in the patients who had previously been treated for distal intestinal obstruction syndrome the period in hospital was substantially shorter (4.7 versus 10.5 days). Like the patients described by Cleghorn et al, ${ }^{9}$ our patients preferred the lavage technique to conventional treatment. Most patients found that the concentrated fruit juice partially disguised the salty taste of the solution and only one patient failed to tolerate it and required $a^{x}$ nasogastric tube. With encouragement all of the patients tolerated the large volumes of fluid ? Although none of our patients vomited, inhalation of vomit could be a major complication were it to occur $\frac{\bar{m}}{\overline{0}}$ For this reason Cleghorn et al did not advocate the use of lavage in complete obstruction. In our case however, it proved remarkably effective when con-s ventional treatment had failed. The length of follow $\overrightarrow{0}$ up has been short, but there is no reason to expect that this method would have additional benefits in influencing recurrence rate.

Although the pathogenesis of distal intestinal obstruction syndrome is probably multifactorial,, t pancreatic maldigestion has always been considered a prerequisite. $^{1-3}$ The occurrence of acute obstruction $\omega_{\infty}$ with typical findings of mucofaecal impaction at lap- aratomy in the absence of pancreatic steatorrhoea might suggest that the defect in anion transport ${ }^{11}$ in $_{C}$ cystic fibrosis is also important. If this is true, then ultimately this may lead to an effective preventive policy. Meanwhile controlling steatorrhoea remains theog only effect method. ${ }^{24}$

In conclusion, we have been impressed by the lavage technique described by Cleghorn et al ${ }^{9}$ fors cases of distal intestinal obstruction syndrome. It has substantial advantages over conventional treatment, with better acceptance by patients and likely savings in time spent in hospital. The syndrome is often recur- $\overrightarrow{0}$ rent, and once the hospital has ensured that steato-3 rrhoea is adequately controlled there may be a role? for self administration at home.

\section{References}

1 Zentler-Munro PL, Hodson ME, Batten JC. Meconium ileus equivalent in older patients with cystic fibrosis. Br Med J 1983;287:501-2.

2 Park RW, Grand RJ. Gastro-intestinal manifestations of cystic fibrosis: a review. Gastroenterology 1981;81:윽 1143-61.

3 di Sant' Agnese P, Davis PB. Cystic fibrosis in adults: $7 \underset{2}{0}$ cases and a review of 232 cases in the literature. $A m J$ Med 1979;66:121-32.

4 Zentler-Munro PL. In: Hodson ME, Norman AP, Batten JC, eds. Cystic fibrosis. London: Ballière Tindall, 1983:155-6.

5 Hodson ME, Mearns MB, Batten JC. Meconium ileuș equivalent in adults with cystic fibrosis of the pan creas: a report of six cases. $\mathrm{Br} M e d J$ 1976;ii:790-1.

6 Hanly JG, Fitzgerald MX. Meconium ileus equivalent inc older patients with cystic fibrosis. $\mathrm{Br}$ Med $\mathrm{J} 1983 ; 286:$ 1411-3.

7 Wagget H, Bishop H, Koop E. Experience with gastrografin enema in the treatment of meconium $\frac{\rho}{9}$ ileus. J Paediatr Surg 1970;5:649-54.

8 Rosenstein BJ, Langbaum TS. Incidence of distal intestinal obstruction syndrome in cystic fibrosis. $J \mathrm{Pae}^{-}$ 
diatr Gastroenterol Nutr 1983;2:299-301.

9 Cleghorn GJ, Stringer DA, Forster GC, Durve PR. Treatment of distal intestinal obstruction syndrome in cystic fibrosis with a balanced intestinal lavage solution. Lancet 1986;i:8-11.

10 Davis GR, Santa Ana CA, Morawaski SG, Fordtran JS. Development of a lavage solution associated with minimal water and electrolyte absorption or secretion. Gastroenterology 1980;78:991-5.

11 Quinton PM, Bijman J. Higher bioelectric potentials due to decreased chloride absorption in the sweat glands of patients with cystic fibrosis. $N$ Engl J Med 1983;308:1185-9.

12 Nelson R, Sharkey I, Beesley JR. Lavage for intestinal obstruction in cystic fibrosis [Letter]. Lancet 1986;i: 1503.

13 Brady CE, DiPalma JA, Morawski SG, Santa Ana CA, Fordtran JS. Urinary excretion of polyethylene $\mathbf{3 3 5 0}$ and sulfate after gut lavage with a polyethylene glycol lavage solution. Gastroenterology 1986;90:1914-8. 